\title{
LA ADAPTACIÓN EN LA ERA INTERMEDIÁTICA: TEXTOS, PANTALLAS E INDUSTRIA
}

\section{ADAPTATION IN A MULTIMEDIATIC ERA: TEXTS, SCREENS AND INDUSTRY}

\author{
Iván Gómez \\ Universidad Ramon Llull \\ ivangg@blanquerna.url.edu \\ José Manuel González Álvarez \\ Universität Erlangen-Nürnberg \\ gonzalvajm@gmail.com
}

\section{Resumen:}

La literatura ha suministrado tramas, temas $\mathrm{y}$ argumentos al cine desde sus orígenes. Ya hace tiempo que desde el mundo académico se habla de un nuevo paradigma en las relaciones entre medios, pues los constantes trasvases que experimentan las historias nos obligan a entender la adaptación como un concepto amplio que no se limita a las relaciones entre literatura y cine. Vivimos en un mundo plagado de relatos y éstos se consumen de muy variadas maneras. Estas nuevas pautas de consumo han provocado a su vez que los creadores de historias sean cada día más receptivos a la posibilidad de pensar una obra como algo traducible o, cuando menos, reconducible a diferentes plataformas $\mathrm{y}$ soportes. El fenómeno de la adaptación es hoy más que nunca un fenómeno intermediático que debe estudiarse atendiendo a las diferentes plataformas y universos de referencia que proveen contenidos, temas y argumentos al cine, medio que, a su vez, es el origen de productos que se desarrollan en otros formatos y medios. No podemos entender correctamente la actual industria del entretenimiento sin analizar atentamente estos constantes trasvases.

\begin{abstract}
:
The literature has provided master plots to cinema from its origins. For many years we spoke about a new paradigm in the relationship between media. The usual exchanges between media compel us to understand adaptation as a broad concept not limited to the relationship between literature and film. We live in a world full of stories and these are consumed in many different ways. These new consumption patterns have changed the creators' mind who are more receptive of thinking their works as something that could travel between different platforms and media. Adaptation is now more than ever an intermedial phenomenon that must be considered on different platforms and universes of reference. The exchanges between cinema, television, literature and videogames are made on a daily basis and we can't understand the present entertainment industry without a close reading of this fact.
\end{abstract}

Palabras claves: cine; literatura; adaptación; intertextualidad; remake.

Key Words: Cinema; Literature; Adaptation; Intertextuality; Remake. 


\section{Un mundo hecho de historias: el fenómeno de la adaptación}

La historia de la industria cinematográfica siempre ha resultado de lo más ilustrativa. Especialmente la de ese lugar algo indeterminado que conocemos como Hollywood, topónimo con el que definimos una maquinaria industrial en casi constante cambio y evolución. La historia de los Estudios ilustra muy bien la relación que esas empresas -hoy auténticos conglomerados industriales multimediáticos- han mantenido con todo aquel elemento o material de base que les ha servido como aceite para su motor ficcional. En otras palabras, los Estudios siempre han entendido qué era eso de la adaptación y la han practicado desde que echaron a andar. Esas grandes empresas, cuyas marcas comerciales, si bien no todas, todavía hoy existen, ocuparon un espacio central en la producción cinematográfica estadounidense desde mediados de los años 20. No eran las únicas empresas que hacían cine, el panorama industrial era, y es, también rico y diverso por mucho que a veces nos cueste comprenderlo, pero sí eran las factorías más importantes. De forma rápida estas empresas entendieron el valor que lo literario podía tener para ellas. La literatura se convirtió en una fuente inagotable de textos y guionistas, aunque seguramente más de lo primero que de lo segundo.

Tomemos como ejemplo los Estudios Universal, que no formaba parte de los Big Five (Paramount, MGM, Fox, Warner Bros. y RKO), pero que junto a la First National y la United Artist tuvo mucho que decir en esos años de formación y consolidación del sistema de Estudios (Koszarski, 2011, p.350). Cuando Carl Laemmle padre "legó" el estudio a su hijo, Carl junior, el jovencísimo magnate, devoto de las historias de horror, adoptó la estrategia comercial de ahondar en las adaptaciones de textos literarios clásicos relacionados con el mundo de lo fantástico. Ese traspaso de poderes ocurrió en 1928, pero previamente Irving Thalberg, niño prodigio muy aficionad a la adaptación literaria, había dirigido la producción entre 1920 y 1923. Ya se había adaptado, por ejemplo, la novela $E l$ fantasma de la Ópera (1910), de Gaston Leroux, y quedaban por llegar las obras literarias Drácula (1897), Frankenstein o el moderno Prometeo (1818) y El hombre invisible (1897), entre otras. Fueron varias las grandes novelas que acabaron convertidas en películas por el nuevo estratega de la empresa. Estas películas buscaban la complicidad de un público rural masivo, devoto 
igualmente de las producciones de bajo presupuesto y de las películas del Oeste (Gabler, 2015, p.371). La Universal no disponía en un primer momento de cines en su poder, por lo que no tenía asegurada la proyección de sus películas ni el acceso a los mejores cines urbanos, muchos de ellos propiedad de los grandes Estudios.

Los Laemmle acabaron perdiendo el control de la Universal unos años después, cuando se tuvieron que endeudar para llevar a cabo otra adaptación, Show Boat (1936), una cinta que el propio estudio había ya producido en una versión anterior, parcialmente sonora, de 1929. Poco antes habían hecho muy buena taquilla con otra adaptación, Sin novedad en el frente (1930), sobre la novela de Erich Maria Remarque. Curiosamente, fue también en 1936 cuando se lanzó la adaptación del popular cómic Flash Gordon en forma de serial cinematográfico. Del cómic habíamos viajado a la gran pantalla, algo que otros pioneros como Windsor McCay ya habían hecho años atrás. Pero todos estos aciertos no fueron suficientes y los Laemmle acabaron cediendo ante los acreedores del Estudio.

Universal pasó numerosas vicisitudes, no es cuestión de repasarlas todas. Pero en momentos clave de su historia la adaptación siguió muy presente. En los años 40 lanzaron una serie de filmes con el mítico Basil Rathbone como Sherlock Holmes. Sin olvidar que Alfred Hitchcock trabajó en diversas ocasiones bajo el sello del estudio, y el director inglés es bien conocido por sus recurrentes adaptaciones de textos literarios considerados habitualmente como menores -no lo era la Rebeca (1938) de Daphne du Maurier, si bien el empeño era muy Selznick y eso explica el prestigio del texto original-. Vértigo. De entre los muertos (Vertigo, 1958), Psicosis (Psycho, 1960) o Los pájaros (The Birds, 1963), fueron adaptaciones, muy libres por cierto, pero adaptaciones al fin y al cabo, basadas en obras muy menores que, además, sólo le sirvieron al maestro inglés como punto de partida.

Desde los tiempos de los Laemmle hasta los del mítico Lew Wasserman, Universal ha conocido bien la técnica de la adaptación como fórmula de capitalización de un material narrativo previo que ha demostrado, con sus matices, una efectividad narrativa y comercial. Y ahí podemos introducir un primer elemento teórico a tener en cuenta: la adaptación ha sido siempre para la 
industria del cine un concepto muy abierto que no puede limitarse al trasvase de lo literario -en cualquiera de sus formas- a la gran pantalla. De hecho, por lo relatado hasta aquí, ya podemos ver algunas fórmulas recurrentes de la adaptación, como puedan ser el paso del cómic -arte tan menor en la mente de no pocos teóricos y académicos- al cine, el remake o incluso el autoremake, también posible, sin contar los seriales o serializaciones de contenidos narrativos -Abbott y Costello fueron fértiles hallazgos de taquilla por parte de Universal, por poner un ejemplo-. Pero aún hay más. Del serial de Flash Gordon se hizo una versión “cinematográfica”, es decir, de la serie se pasó a una película que resumía lo mejor del serial, técnica que, salvando las distancias de formato, el espectador contemporáneo conoce bien gracias a tantas cintas que hoy día hacen lo propio - con fortuna muy cambiante, todo sea dicho-. También podríamos recordar que Show Boat, la versión da igual y se han hecho varias, viene de una novela de Edna Farber pero también del musical del dúo creativo Kern-Hammerstein. La versión de 1936, por cierto, es la más fiel al musical, mientras que las de 1929 y 1951 son mucho más libres. Así que tenemos una buena cantidad de posibles variables de la adaptación ejemplificadas en la actividad industrial de Universal. Novela, teatro -el Drácula de Browning era una adaptación tanto de la novela original como de la obra teatral que ya había triunfado en EE.UU., y no olvidemos la versión de Melford en español-, musicales, cuento, cómic, el remake, seriales pasados a película y, cómo no, hechos históricos. En puridad nos faltarían los videojuegos y ya tendríamos casi todas las modalidades posibles de trasvases entre formatos, siempre que consideremos los seriales como prototelevisión, algo muy laxo cuando no erróneo, pero que nos sirve de momento para entender la mentalidad comercial de estos pioneros de la industria del entretenimiento.

Durante esos años que hemos referido muy brevemente cualquier aproximación teórica que podamos imaginar o conceptualizar sobre el fenómeno de la adaptación nace de la propia práctica. Los guionistas y productores ejecutivos entendieron rápidamente que el lenguaje visual del cine podía reelaborar casi cualquier material previo, pero que cada medio contaba con sus normas y que si algo podía conducir al desastre era precisamente el aproximarse a la escritura del guión y a la posterior puesta en escena cargado de pleitesías -pensemos en 
los difíciles ejemplos de Erich von Stroheim o en David O. Selznick, por citar dos casos-. Pero también es cierto que no pocos creadores seguían reverenciando el poder de lo literario por encima de casi cualquier otro material de base, como si el libro pudiese suministrar de manera directa un "barniz intelectual” (Peña-Ardid, 1992, p.22). En esa tensión latente entre el reconocimiento y el buen uso del original y la necesaria apropiación que debe realizar todo adaptador radica la clave del trabajo de adaptación. Es por ello que podríamos aventurar que

La buena adaptación es la que, sin dejar de lado ningún elemento significativo del original, consigue hacer olvidar el material de referencia al lograr una cierta traducción (translación/transposición) que mezcle en un mismo relato la fuerte presencia del autor fílmico y la (significativa) ausencia del escritor que hay detrás (De Felipe; Gómez, 2008, p.46).

Para no pocos creadores ha resultado siempre esencial encarar ese trabajo de adaptación como una auténtica apropiación del material de origen (Vanoye, 1996, p.149). Técnicas hay muchas, y al examinar las palabras de los creadores encontramos una infinidad de detalles y opiniones sobre el fenómeno, pero muchos insisten en la necesaria traducción más o menos libre de lo textual a lo visual. John Huston, por citar un ilustre ejemplo, ya hablaba a propósito de la inabarcable Moby Dick de penetrar en la idea básica del texto para luego traducirla a términos cinematográficos. Lo esencial sería aquí averiguar las emociones que intentaba transmitir Melville en cada momento y buscar una adecuada manera de traducirlo en imágenes y diálogos (en Aresté, 2006, p.63). Más allá de los criterios que usemos para analizar la fidelidad a la obra original, lo que parece evidente es que toda adaptación deberá integrarse en un formato del que necesitamos conocer bien sus normas de funcionamiento. En otro caso corremos el riesgo de perdernos irremediablemente entre traducciones imposibles o lenguajes irreductibles entre sí.

\section{Adaptación e industria}

Así las cosas cabe plantearse si en los tiempos actuales tiene sentido limitar y circunscribir el estudio del concepto de adaptación al trasvase estricto entre 
literatura y cine. Es más, ¿lo tiene a la vista de cómo se ha utilizado industrialmente la adaptación de materiales previos a la pantalla de cine a lo largo de la historia del medio? Incluso si desde el terreno de lo puramente teórico hablamos de trasvases filmoliterarios, ¿es posible hoy día analizar la adaptación olvidando videojuegos, televisión o cómic? ¿No es el remake una forma de adaptación como otra cualquiera? Este concepto amplio de adaptación ya lo defendimos hace algunos años en otro texto (De Felipe, Gómez, 2008), pero la idea hacía tiempo que fluía libremente por obras de autores como Robert Stam, quien ya habló de un complejo de clase para referirse a ese gran prestigio que tenía la literatura como fuente "adaptable" frente a otras artes consideradas menores (Stam, 2005). Se diría que Stam era un atento lector de historia, y que conocía bien ese complejo de inferioridad con el que alguien tan poliédrico como David O. Selznick luchaba a brazo partido, acudiendo precisamente a la alta literatura como fuente de inspiración para sus megalómanas producciones ${ }^{1}$. La literatura ha funcionado habitualmente como una fuente de legitimación cultural, que se lo pregunten a Louis B. Mayer, por ejemplo. O a Irving Thalberg. La literatura les dio lo que nunca pudieron ganar en la universidad o en el mundillo de los creadores, legitimidad cultural. Vendían sueños, sí, pero literarios. Ese mismo problema ya lo advirtió Concepción Cascajosa cuando se enfrentó a la adaptación en su imprescindible El espejo deformado. La doctora Cascajosa lidia recurrentemente con la televisión, por lo que sabe muy bien de lo que habla cuando se refiere a términos como "legitimación cultural”2.

Así que, ¿por qué limitar lo filmoliterario a los trasvases entre literatura y cine? ¿No estamos acaso hablando del fenómeno de la adaptación en sentido amplio? ¿No es la adaptación cualquier trasvase de corte textual de un medio a otro? A este problema se enfrentaron también Pedro Javier Pardo y Javier Sánchez Zapatero cuando organizaron en el 2012 en la Universidad de Salamanca un

\footnotetext{
1. Recordemos que Selznick es el responsable de adaptaciones como la de Ana Karenina (Anna Karenina, Clarence Brown, 1935), Historia de dos ciudades (A tale of two cities, Jack Conway, 1935) o David Copperfield (George Cukor, 1935), todas ellas basadas en obras de referencia. Una parte importante de sus desacuerdos con Hitchcock a propósito de la adaptación de Rebecca provenían de la diferente manera que ambos creadores tenían de enfocar la adaptación. 2. Uno de los capítulos de su reciente ensayo La cultura de las series (Laertes, 2016) se adentra en los mecanismos a través de los que algunos críticos y teóricos han pensado e intentado legitimar a televisión como objeto de estudio y también en las relaciones que algunos autores literarios han mantenido con el medio.
} 
simposio sobre las relaciones entre literatura y cine que subtitularon "más allá de la adaptación”. De aquel simposio surgió un interesante libro publicado poco después que en su prólogo nos habla de estas cuestiones (Pardo, Sánchez Zapatero, 2014, p.11). Los autores comentan precisamente lo difícil que fue obtener intervenciones para el simposio que, hicieran bueno ese polémico subtítulo. A través de unas líneas temáticas que entendieran la adaptación en un sentido lo más amplio posible pudieron reciclar creativamente algunos conceptos, como la intertextualidad de Genette, en su búsqueda de un nuevo paradigma de la adaptación. Un paradigma que ya no sería únicamente narrativo, sino también discursivo, y más genérico que genético (Pardo, Sánchez Zapatero, 2014, p.12). El objetivo era evitar que la adaptación se entendiese exclusivamente como el viaje de la literatura al cine y como una relación de parentesco fuerte entre textos hermanos.

Hoy día abundan los ensayos en los que se intenta adaptar de manera más o menos creativa ese nuevo paradigma y es sencillo encontrar análisis de la adaptación al cine de mitología, textos religiosos o históricos, además de novela, cuento y teatro. Sigue siendo algo más complicado encontrar estudios sobre trasvases entre cómic y cine, o entre televisión y cine. Los estudios sobre televisión se suelen centrar en el medio más que en los trasvases. Y sobre remakes sigue habiendo poca literatura académica en español e incluso no es el territorio más transitado por los autores anglosajones. El paradigma de lo literario sigue pesando mucho. Algo que no encaja bien con la propia estructura del negocio cinematográfico de las majors en EE.UU., como supo ver Esteve Riambau en su imprescindible Hollywood en la era digital. En ese ensayo Riambau dedica todo un capítulo a los remakes, sabedor de que esta forma particular de adaptación está alimentando la maquinaria cinematográfica de EE.UU.

Los productores estadounidenses han engrasado bien un sistema de adaptaciones constantes, copias más o menos indisimuladas, remakes, puestas al día y traducciones para otros mercados cinematográficos. En pocas palabras: se muestran especialmente dispuestos a volver a hacer o traducir todo aquel material narrativo que ha demostrado previamente su éxito o buen funcionamiento. Con algunos matices, por supuesto. Hoy día una parte esencial 
del mercado cinematográfico por el que compiten las películas norteamericanas es el asiático y más concretamente, el chino. No son pocos los filmes que se rehacen pensando en ese mercado y en otros emergentes, de manera que asistimos a actualizaciones, más o menos innecesarias aunque siempre interesantes de ver, como RoboCop (José Padilha, 2014), Desafío Total (Total Recall, Len Wiseman, 2012), Mad Max: Furia en la carretera (Mad Max: Fury Road, George Miller, 2015) o hasta The Karate Kid (Harald Zwart, 2010). Esta última es la perfecta demostración del "síntoma chino", puesto que la acción está directamente ambientada en China mientras que la edad de los protagonistas se ha reducido considerablemente. No le faltan argumentos a quienes defienden que el cine de consumo masivo estadounidense se ha infantilizado demasiado, aunque industrialmente se haya refinado $\mathrm{y}$ perfeccionado3.

De todos es sabido que los espectadores de casi todo el mundo ven cine estadounidense pero que los propios ciudadanos de EE.UU. no ven cine de ningún otro país que no sea el suyo - nos referimos a los grandes públicos-. Los mejores éxitos coreanos, se adaptan; los japoneses, también. Películas con estándares de producción altísimos, caras, bien facturadas, repletas de acción pero habladas en coreano, chino o japonés, son hechas de nuevo para el mercado anglosajón y europeo. Así es como las empresas que rehacen esos éxitos acaban sacando tajada de una adaptación muchas veces innecesaria desde el punto de vista artístico, pero no así desde el industrial. La exitosa Train to Busan (Busanhaeng, Sang-ho Yeon, 2016), una buena historia de zombies ambientada en Corea y que recibió premios en el Festival de Cine Fantástico de Sitges, tendrá un remake en inglés. Lo curioso es que lo hará la francesa Gaumont, en este caso, como parte de su estrategia para expandirse internacionalmente. Ya veremos si su sede en Los Ángeles dura mucho, pero de momento han entendido bien a qué se dedican sus competidores.

Se entenderá así que en este mundo industrialmente tan complejo y cambiante, la adaptación de contenidos sea un territorio muy marcado por cuestiones que

\footnotetext{
3. Sobre la relación entre el mercado estadounidense y el chino y la adaptación de los productos cinematográficos al gusto de espectadores internacionales cabe consultar, por la agudeza de sus análisis y porque una parte importante del estudio se basa en entrevistas con creadores, el jugoso ensayo The time of my life (Blackie Books, 2016), de la periodista Hadley Freeman.
} 
tienen que ver más con el dinero que con la creatividad. Los creadores han hecho siempre gala de una portentosa imaginación a la hora de reciclar y readaptar contenidos, pero siempre han tenido que entenderse con una industria que conoce el dinero mucho más que a Upton Sinclair. Esto no es tanto un reproche como una constatación. En este terreno de juego la literatura sigue teniendo una papel muy importante, casi diríamos que central, como suministradora de contenidos. Se siguen comprando y vendiendo derechos de adaptación, se persiguen opciones preferentes sobre novelas y éxitos teatrales. Los cómics también han empezado a jugar en esta liga, algo lógico en tiempos de resurgimiento de superhéroes cinematográficos. Frank Miller es hoy un escritor de cómic adaptado y bien valorado, Wes Anderson utiliza cuentos de Stefan Zweig para El gran hotel Budapest (The Grand Budapest Hotel, 2014), y la televisión recicla sin parar; a Sherlock Holmes con notable éxito, por citar algo muy conocido que también ha vuelto al cine mainstream. La literatura sigue contando, y mucho, pero la televisión, los remakes y los videojuegos ganan terreno.

Así es la industria. Una máquina de reciclaje que lo fagocita todo porque tiene que satisfacer a nuevos espectadores constantemente y que vive atrapada por la acuciante necesidad de detectar los relevos generacionales. Casi se diría que cada nueva generación merece su Mad Max, o su Terminator, o su Sherlock Holmes, porque los nuevos espectadores no viajan hacia atrás, no les interesa. Sólo miran hacia adelante. Puede que esa sea la razón por la que siempre cabrá un Shakespeare más, o un Chandler, o un Asimov. O nuevas visiones basadas en Tolkien. Son valores seguros cuyas adaptaciones acaban siendo comparadas con ellas mismas ya que el espectador medio desconoce, en términos generales, las anteriores, por no hablar de los textos de referencia. Matrix (Wachowski Bros., 1999) es ya una película "vieja". Tiene unos dieciocho años. Para el mercado cinematográfico eso es demasiado, por lo que necesita ser reactualizada. Quizás aquí activarán el mecanismo de la ampliación del universo narrativo, para evitar un simple remake. Pero no nos engañemos, el objetivo final de estas actualizaciones es incorporar a ese universo a todos aquellos espectadores que no vieron el original. Algunas sagas de superhéroes han funcionado así en los últimos tiempo, hasta que nos despistamos y nos encontramos viendo un 
reboot, esa especie de eterno retorno cinematográfico en el que acabas preguntándote si esa película no será la misma que ya viste, con los colores y los actores cambiados. Para los próximos dos años están previstos remakes de $E l$ Rey León, Mulan, Peter Pan, Dumbo, la mítica It, y hasta de Dirty Dancing.

Ciertamente es un error pensar que adaptación es sinónimo de Hollywood y de mercado estadounidense. Todas las cinematografías conocen la adaptación y la practican, desde la española a la húngara. Ni el cine ni la adaptación fueron inventados por las majors. Pero sí es cierto que es el mercado estadounidense el que marca tendencia y el que acaba decidiendo el aspecto de las carteleras de medio mundo. Además su potencia industrial está estrechamente relacionada con el fenómeno del remake, los trasvases entre televisión y cine y con el rentable mercado del videojuego. De la misma manera el gusto de un público muy numeroso está formado y conformado a partir del consumo de ese tipo de productos masivos, por lo que no podemos entender bien el fenómeno de la adaptación sin el estudio del mercado más potente que hoy día la está practicando de manera constante, es decir, el estadounidense.

\section{Adaptación: aproximaciones}

Tras estas consideraciones generales, sería bueno resumir brevemente las aproximaciones con las que se ha construido la presente edición. Como veremos sigue pesando notablemente el concepto de adaptación literaria, pero también vamos a encontrar aportaciones que hablan de la televisión o de los videojuegos. Repasemos mínimamente el contenido del número.

Vicente de Jesús Fernández Mora pone su atención en la película Vámonos con Pancho Villa (Fernando de Fuentes, 1936), emblemática producción con la que el aparato cultural mexicano quiso reivindicar los pilares fundadores de la Revolución. El film, basado en la novela homónima de Rafael Muñoz (1931), se encuadra dentro de la “Trilogía de la Revolución” rodada por De Fuentes y pone sobre la mesa las tensiones y contradicciones del discurso triunfalista construido por las élites culturales. El extenso y documentado trabajo de Fernández Mora aporta, además de un análisis fílmico-literario, claves socioculturales que enriquecen notablemente el marco histórico de partida. 
Paul Quinn, por su parte, aborda la adaptación cinematográfica que Luis Buñuel lleva a cabo de Ensayo de un crimen (1944), novela de Rodolfo Usigli. El trabajo abunda en los nexos intertextuales e intermediales de ambas piezas, haciendo énfasis en las nociones de apropiación y transformación, y extrapolándolas a otras adaptaciones buñuelianas durante su periodo mexicano. Quinn ofrece, así, un análisis de "los mecanismos movilizados durante el proceso de traslación de la página a la pantalla” desde una vertiente sobre todo formal y semiótica, sin excluir la psicoanalítica e ideológica.

Jorge Jimeno Aranda se decanta por estudiar las conexiones entre biografía, literatura y guiones cinematográficos, recalando para ello en la figura relevante de Jorge Semprún. El estudio cubre un cierto vacío bibliográfico respecto a la faceta del Semprún cineasta, prestando atención tanto a su labor de guionista como a la dirección de su único filme documental. Aranda se propone así hacer un recorrido analítico que demuestre la hibridez de la obra sempruniana, en tanto mezcla de recreación ficcional, biografía y memorialismo.

Julia González de Canales nos brinda un análisis de alta densidad teórica en torno a la adaptación fílmica, y más particularmente centrado en la apropiación que de los clásicos literarios lleva a cabo el director catalán Albert Serra. De los siete largometrajes que el cineasta lleva a sus espaldas, la autora se acerca a tres de ellos como botón de muestra para situar "la obra fílmica de Serra como un producto altamente original, capaz de beber de la fuente literaria a la vez que transformar su valor artístico en un producto cinematográfico independiente y autónomo".

Partiendo de la hibridación y ambigüedad como ejes estructurales de la expresión artística, Mario de la Torre reflexiona sobre la teatralidad dentro del código cinematográfico, aplicando la teoría de los polisitemas como metodología para emprender un análisis de la intertextualidad e intermedialidad en el cine almodovariano. Más concretamente, se sostiene la hipótesis de que "la teatralidad en el cine de Almodóvar es el resultado del uso activo del repertorio cultural disponible en España entre los cincuenta y finales de siglo y siguiendo siempre unas determinadas normas que la hacen alejarse de la verosimilitud teatralizante". 
Aimée Mendoza nos traslada al universo del cineasta checo Jan Švankmajer para abordar la película Kyvadlo, jáma a naděje (1983). El título es, en rigor, una adaptación de los relatos "El pozo y el péndulo" (1842) de Edgar Allan Poe y "La tortura por la esperanza” (1888) de Auguste Villiers de L'Isle Adam. Su autora hace énfasis en las relaciones intermediales de ambos textos literarios fantásticos, de cuya intersección resulta el cortometraje de Švankmajer. La incidencia de la estética surrealista y del teatro de marionetas de Praga sirven como herramientas para efectuar una lectura del montaje y del sonido, así como un análisis narratológico de la adaptación.

Por su parte, Marta Frago nos introduce en el subgénero del biopic mediante un acercamiento a La red social (David Fincher, 2010) y Steve Jobs (Danny Boyle, 2015), biografías de figuras notorias de la revolución digital, como son el mentado Jobs y Mark Zuckerberger. La autora se proyecta sobre la labor de su guionista, Aaron Sorkin, recalcando las concomitancias de ambas propuestas fílmicas. Este asigna a los protagonistas una serie de rasgos dramáticos ligados a personajes de la literatura universal, lo cual hace más complejas las aristas de significado, que es "handled like a mask which hides the individual; thus these movies create an illusion of unmasking, of showing what lies "behind" the popularity and recognition of the celebrity”.

Irene Raya elige el binomio terror cinematográfico/serie televisiva para “aterrizar” en el caso de la serie Scream (MTV, 2015) y ese trasvase intermedial. El artículo contiene un repaso general de los temas y formatos que la ficción televisiva tomó del cine, así como de las dificultades que entraña dicha adaptación. Desde el prisma metodológico de los Estudios culturales, la Narrativa audiovisual y la Teoría de los géneros, Raya emprende un detallado análisis de Scream para concluir que "la serie cumple los códigos generales del neo slasher, sobre todo en lo concerniente a la autoconsciencia del género y el bagaje de la audiencia, jugando con esas ideas preconcebidas para tratar de crear sorpresas".

Ángel del Río comienza examinando el concepto de monstruosidad para después extrapolarlo a las nociones de intermedialidad, y especialmente "al discurso transversal que ofrece la serie animada Los Simpson (Matt Groening)”. 
En particular, el trabajo se centra en el proceso de adaptación perceptible en dos capítulos donde se reescriben sendas versiones del monstruo: Bart Simpson's Drácula, que dialoga con Bram Stoker y Nightmare on Evergreen Terrace, en clara conexión con Nightmare on Elm Street, de Wes Craven.

Mikel Peregrina se encarga de diseccionar la adaptación cinematográfica que de los mitos de Cthulhu (H.P. Lovecraft) lleva a cabo el cineasta español José Luis Alemán. En concreto, se pasa revista al díptico formado por La herencia Valdemar (2010) y La sombra prohibida (2011) para desarrollar aspectos como las fidelidades o las desavenencias de ambos títulos respecto a la ficción lovecraftiana, y sobre todo las dificultades en su traslación al cine, que reportaron a una y otra película una recepción negativa de crítica y público. Se logra de esta manera desentrañar "cuál es la parte de la obra del maestro de Providence que ha sobrevivido en el imaginario colectivo, es decir, cuál ha sido el método por el que se ha producido este trasvase cultural concreto”.

Al terreno de lo videolúdico se desplaza el aporte de Juan Luis Lorenzo, quien profundiza en el concepto de transmedialidad a propósito del videojuego The Warriors (2005), basado en la novela de Sol Yurick (1965). Lorenzo nos entrega un estudio pródigo en consideraciones teóricas y contrastivas sobre lo intertextual e intermedial, puesto que a novela y videojuego se suman una adaptación cinematográfica y una versión en cómic que son también objeto de análisis. Todo ello se constituye en una sugestiva saga transmedial donde "el videojuego se convierte en un vehículo, gracias a su particular idiosincrasia, que permite una experiencia inmersiva en una narración multiplataforma”.

Como puede apreciarse se ha intentado ofrecer un panorama amplio del fenómeno de la adaptación y si bien el remake se nos ha quedado fuera de los análisis individuales, hemos intentado compensar su falta con una reflexión general a partir del análisis de la realidad actual del mercado cinematográfico. Por mucho que queramos huir de ello, el mercado tiene unas normas y cuando hablamos de cine, necesariamente, tenemos que hablar de la relación entre arte e industria, creatividad y dinero. Desde tiempos muy tempranos ha sido así, y parece que esa relación goza de buena salud en estos tiempos de mercados globalizados. 


\section{Referencias bibliográficas}

Aresté, J.M. (2006). Escritores de cine. Madrid: Espasa-Calpe.

Cascajosa, C. (2006). El espejo deformado. Versiones, secuelas y adaptaciones en Hollywood. Sevilla: Universidad de Sevilla.

Cascajosa, C. (2016). La cultura de las series. Barcelona: Laertes.

De Felipe, F.; Gómez, I. (2008). Adaptación. Barcelona: Extensiones.

Freedman, H. (2016). The time of my life. Barcelona: Blackie Books.

Gabler, N. (2015). Un imperio propio. Cómo los judíos inventaron Hollywood. Almería: Confluencias. Edición original de 1988.

Koszarski, R. (2011). El cine de los años 20. En Brunetta, G.P. Historia mundial del cine I. Estados Unidos. Madrid: Akal. Edición original de 1999.

Pardo, P.J.; Sánchez Zapatero, J. (2014) (eds.). Sobre la adaptación y más allá: trasvases filmoliterarios. Salamanca: Ediciones de la Universidad de Salamanca.

Peña-Ardid, C. (1992). Literatura y cine. Madrid: Cátedra.

Riambau, E. (2011). Hollywood en la era digital. Madrid: Cátedra.

Stam, R. (2000). Teorías del cine. Barcelona: Paidós.

Stam, R.; Raengo, A. (eds.) (2005). Literature and film: A guide of the Theory and Practice of Film Adaptation. Oxford: Blackwell.

Vanoye, F. (1996). Guiones modelo y modelos de guión. Barcelona: Paidós.

Cómo citar: Gómez, I. y González Álvarez, J.M. (2017). La adaptación en la era intermediática: textos, pantallas e industria. Fotocinema. Revista científica de cine y fotografia, $\mathrm{n}^{\mathrm{o}}$ 14, pp. 5-18. Disponible: http://www.revistafotocinema.com/ 